World Lumen Congress 2021 | May 26-30, 2021 |

Iasi, Romania

\title{
Design of Experimental Research on the Formation of Nonverbal Communication Skills and Impression Management of Police Officers
}

\author{
Lucia BÎTCA
}

https://doi.org/10.18662/wlc2021/06

How to cite: Bîtca, L. (2021). Design of Experimental Research on the Formation of Nonverbal Communication Skills and Impression Management of Police Officers. In A. Sandu (vol. ed.), Lumen Proceedings: Vol. 17 World Lumen Congress 2021 (pp. 53-57). Iasi, Romania: LUMEN Publishing House. https://doi.org/10.18662/wlc2021/06 


\title{
Design of Experimental Research on the Formation of Nonverbal Communication Skills and Impression Management of Police Officers
}

\author{
Lucia BÎTCA ${ }^{1}$
}

\begin{abstract}
Increasing competition in the organizational environment and strengthening buman capital can greatly contribute to the ability to close existing gaps in the development process and ensure a more competitive level, and the professional development process includes not only setting career goals and training agreements, but also evaluations and the feedback needed to assess progress. By optimizing nonverbal skills and forming impression management strategies promoted by psychological training in enhancing the knowledge and skills of police employees, they serve as a basis for organizational projects designed to facilitate self-realization of internal potential and stimulate their involvement in the organization. Organizational behavior is the study of the behaviors of individuals, which involves understanding, predicting and controlling human behavior, models and structures, in order to improve the environment, performance and efficiency of the organization. The original of this paper is that the research results led to the identification of components and mechanisms for producing change at the macro-, meso- and micro social level, which uses a perpetual mobilization of social actors in organizations. Another novelty, for a wider geographical area of scientific research, is the application of an intervention methodology in the training impression management strategies through nonverbal communication, with the purpose and purpose in developing relational skills and optimizing professional activity. The information obtained in research on nonverbal communication and impression management tactics on the organizational environment, can be applied for the development of programs for organizational counseling activities, business coaching and large-scale developmental training, promoted through managerial and corporate profile.
\end{abstract}

Keywords: Nonverbal communication, impression management, self-promotion, consideration, exemplification, supplication, intimidation.

$1 \mathrm{MA}, \mathrm{PhD}$ student Free International University of Moldova, Chisinau, the Republic of Moldova, email: luciabitca@gmail.com 


\section{Introduction}

The purpose of the research was to identify the role of psychological training in enhancing the knowledge and skills of police employees on nonverbal communication and its influence on impression management. The subject of the research was the tactics of impression management and nonverbal communication ability, measured at the pre- and post training stage of acquiring knowledge about them and developing the use abilities in professional communication. The methods and tools used in the research were: The Nonverbal Communication Capacity Assessment Questionnaire and the Impression Management Self-Assessment Inventory - built by the author and validated for this purpose.

\subsection{Description of the research sample}

The research presented in this article tested 50 employees from the central and regional subdivisions of the General Inspectorate of Police of the Republic of Moldova, of which 26 women (52\%) and 24 men (48\%), aged between 21 and 40 years, of which 21-25 years old - 18 (36\%); aged 2635 years - $24(48 \%)$, and $36-40$ years $-4(16 \%) .25$ respondents made up the experimental sample, 25 - control.

\subsection{Research design}

The research was carried out on three experimental, ascertaining, formative and control assemblies. The first assembly - experimental involves a research to identify the quality of measured skills, in this case the respondents in the experimental and control group.

\subsection{Research results}

If the parametric conditions are not met between two dependent (correlated) groups, The Wilcoxon non-parametric difference comparison test was applied, which has the same principles as the dependent $t$ test, which determined the size of the differences before and after conducting the training of impression management skills in terms of nonverbal communication, ordered by rank.

Therefore, the scores (transformed into ranks) obtained from the questionnaire applied to the same experimental group at two different times, identifying the differences between the ranks obtained before organizing the training experiment (pretest) and after conducting the training of impression management skills in terms of communication nonverbal (posttest). From the data analysis a statistically significant difference is observed between the 


\section{Lucia BÎTCA | Lumen Proceedings 17 | WLC 2021}

two conditions $(\mathrm{z}=-3.076, \mathrm{p}=0.002)$. These results illustrate that the values obtained are highly significant $(\mathrm{p}<0.01)$ for nonverbal communication ability (Tab.1).

Table 1. Level of significance of statistical differences in the results obtained by applying the nonverbal communication skills assessment questionnaire

\begin{tabular}{|c|c|}
\hline$Z$ & $-3,076^{\mathrm{a}}$ \\
\hline Asymp. Sig. (2-tailed) & $\mathbf{, 0 0 2}$ \\
\hline
\end{tabular}

a. based on positive ranks

For the impression management self-assessment inventory, we calculated the differences between the ranks obtained before and after the organization of the training experiment (Tab. 2).

Table 2. Level of significance of statistical differences in the results obtained by applying the impression management self-assessment inventory

\begin{tabular}{|l|c|c|}
\hline & $Z$ & Asymp. Sig. (2-tailed) \\
\hline Self-promotion & $-2,699^{a}$ & $\mathbf{, 0 0 7}$ \\
\hline Intimidation & $-2,333^{a}$ & $\mathbf{, 0 2 0}$ \\
\hline
\end{tabular}

a. based on positive ranks

As a result of the training, the ability to self-promote increased, but the tendency to use intimidation in impression management decreased. The data obtained indicate $z=-2,699, p=0.007$, and for intimidation - the strategy with which people want to seem more severe, tougher in order to be perceived by others as authoritarian, the data denotes $z=-2.333, p=0.02$, which indicates significant differences statistically between the two conditions (pretest and posttest) of the training participants. For the other impression management tactics, such as consideration, exemplification and supplication, no statistically significant differences are noticed (Fig. 1).

Pretest $\quad$ Posttest

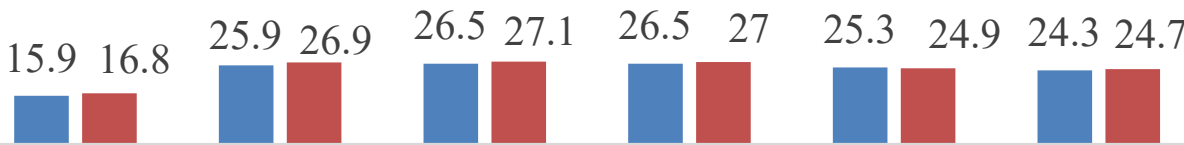

Nonverbal Self-promotion Consideration Exemplification Indimidation Suplication communication

Fig 1. Pre- and posttest results in the experimental group

The non-parametric test (Mann-Whitney test) was used to analyze the differences in the initial scores obtained in the experimental and control 
groups, given the small number of participants for the two categories - 25 each. As shown by the statistical results, no a statistically significant difference, which denotes a similar development of the level of knowledge of nonverbal communication and its ability to decipher / use ( $p=0.907)$, as well as for impression management tactics appreciated through the impression management self-assessment inventory: self-promotion ( $\mathrm{p}=$ $0.784)$, consideration $(p=0.876)$, exemplification $(p=0.961)$, intimidation $(\mathrm{p}=0.922)$, supplication $(\mathrm{p}=0.922)$.

To see if there are changes in the statistical results (Fig. 2), we calculated the differences between the ranks obtained after the organization of the training experiment (posttest) compared to the results obtained by the control group, using the U Mann-Whitney test. The changes in scores in the control group were not substantial, and the scores in some cases, probably arising from certain organizational or personal considerations, were even more unfavorable.

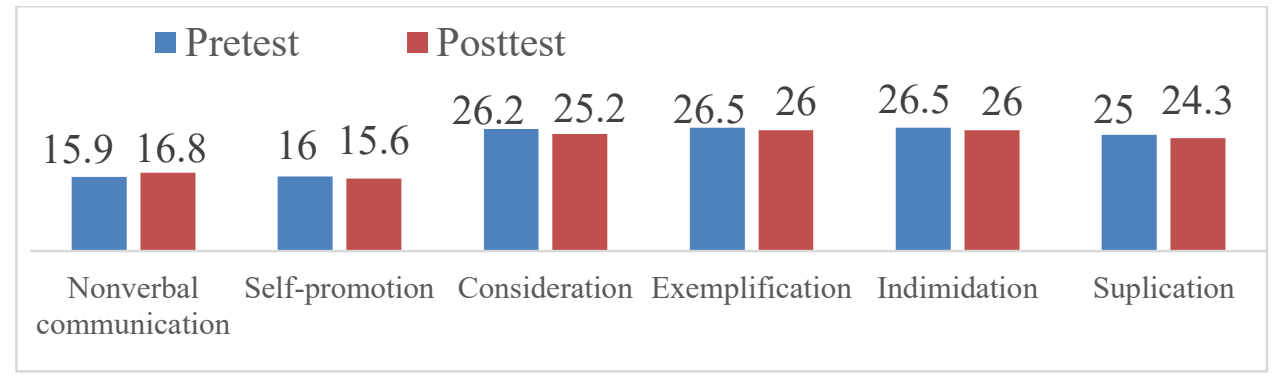

Fig 2. Pre- and posttest results in the experimental group

The statistical results for the nonverbal communication skills assessment questionnaire illustrate a statistically significant difference between the scores obtained by the experimental and the control group ( $p=$ 0.001), noting an improvement in the training result. At the same time, statistically significant differences were identified in terms of scales: selfpromotion $(\mathrm{p}=0.001)$, consideration $(\mathrm{p}=0.002)$, exemplification $(\mathrm{p}=$ $0.29)$, intimidation $(p=0.005)$ and supplication $(p=0.005)$ from the Impression Management Self-Assessment Inventory.

Table 3. Statistical results for the post-test comparison of the results of the experimental and control groups

\begin{tabular}{|c|c|c|}
\hline $\begin{array}{c}\text { Posttest: } \\
\text { experimental -control }\end{array}$ & $\mathbf{Z}$ & $\begin{array}{c}\text { Asymp. Sig. } \\
\text { (2-tailed) }\end{array}$ \\
\hline Nonverbal communication & $-3,371^{a}$ & $\mathbf{, 0 0 1}$ \\
\hline Self-promotion & $-3,244^{a}$ & $\mathbf{, 0 0 1}$ \\
\hline Consideration & $-3,147^{a}$ & $\mathbf{, 0 0 2}$ \\
\hline
\end{tabular}


Lucia BÎTCA | Lumen Proceedings 17 | WLC 2021

\begin{tabular}{|c|c|c|}
\hline Exemplification & $-2,182^{\mathrm{a}}$ & $\mathbf{, 0 2 9}$ \\
\hline Indimidare & $-2,790^{\mathrm{a}}$ & $\mathbf{, 0 0 5}$ \\
\hline Suplication & $-2,799^{\mathrm{a}}$ & $\mathbf{, 0 0 5}$ \\
\hline
\end{tabular}

a. based on positive ranks

Given that nonverbal behavior is influenced by several variables, such as culture, status, gender, individual personality, social and professional context (Turnley, Bolino, 2001) nonverbal communication implies a certain degree of ambiguity; although in many situations this type of communication may convey revealing the meanings, in others it may be sufficiently indeterminate, and some interpretations may not be entirely correct (Tedeschi, 1981). So, in order to correctly discern a meaning of nonverbal communication, one must also take into account the context, the development of the relationship with the transmitter, as well as one's own emotional state at that moment.

\section{Conclusions}

In conclusion, we can note that, as research finds a relationship between nonverbal communication skills and impression management, by developing nonverbal communication skills we will improve impression management skills. The results of the research could be significant for future research to determine other important factors that increase the quality of the exercise of professional functions, by presenting a favorable image in the organizational environment and opportunities for professional development.

\section{References}

Tedeschi, J. T. (1981). Impression management theory and social psychological research. New York: Academic.

Turnley, W. H., \& Bolino, M. C. (2001). Achieving desired images while avoiding undesired images: Exploring the role of self-monitoring in impression management. Journal of Applied Psychology, 86(2), 351-360. https://doi.org/10.1037/0021-9010.86.2.351 